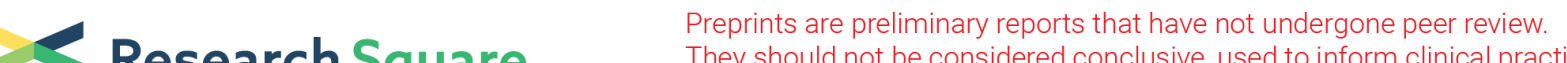 $\begin{array}{ll}\text { Research Square } & \text { They should not be considered conclusive, used to inform clinical practice, } \\ \text { or referenced by the media as validated information. }\end{array}$
}

\section{Airway Management for Penetrating Head and Neck Trauma, Experience of a Trauma Center from 2012 to 2020}

Jean-Baptiste Morvan ( $\boldsymbol{D}_{\text {jbmorvan@hotmail.com })}$

Military Teaching Hospital Sainte Anne: HIA Sainte Anne https://orcid.org/0000-0001-5547-2978

Pierre-Julien Cungi

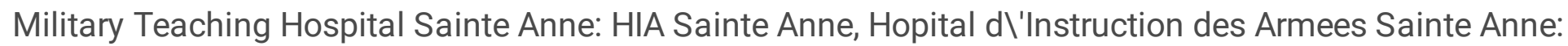
HIA Sainte Anne

\section{Jean Cotte}

Military Teaching Hospital Sainte Anne: HIA Sainte Anne, Hopital d ${ }^{\prime}$ 'Instruction des Armees Sainte Anne: HIA Sainte Anne

\section{arnaud cassignol}

Hôpital Sainte Musse: Hopital Sainte Musse

\section{Aurélien Renard}

Hôpital Sainte-Anne: Hopital Sainte-Anne

\section{Claire-Marie Bussone}

Military Teaching Hospital Sainte Anne: HIA Sainte Anne

\section{Victorine Maso}

Military Teaching Hospital Sainte Anne: HIA Sainte Anne, Hopital d'Instruction des Armees Sainte Anne:

HIA Sainte Anne

\section{Damien Pascaud}

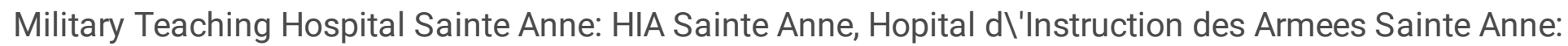
HIA Sainte Anne

\section{Nathan Beucler}

Military Teaching Hospital Sainte Anne: HIA Sainte Anne, Hopital d'Instruction des Armees Sainte Anne: HIA Sainte Anne

\section{Loraine Vatin}

Military Teaching Hospital Sainte Anne: HIA Sainte Anne, Hopital d'Instruction des Armees Sainte Anne: HIA Sainte Anne

\section{Damien Rivière}

Military Teaching Hospital Sainte Anne: HIA Sainte Anne, Hopital d'Instruction des Armees Sainte Anne: HIA Sainte Anne

\section{Christophe Joubert}


Military Teaching Hospital Sainte Anne: HIA Sainte Anne, Hopital d'Instruction des Armees Sainte Anne: HIA Sainte Anne

\section{Olivier Cathelinaud}

Military Teaching Hospital Sainte Anne: HIA Sainte Anne, Hopital d'Instruction des Armees Sainte Anne: HIA Sainte Anne

\section{Julien Bordes}

Military Teaching Hospital Sainte Anne: HIA Sainte Anne, École du Val-de-Grâce: Ecole du Val-de-Grace

\section{Original research}

Keywords: Penetrating head and neck trauma, Airway management, Orotracheal intubation, Cricothyroidotomy, Firearm trauma, Trauma Center

Posted Date: July 8th, 2021

DOl: https://doi.org/10.21203/rs.3.rs-642538/v1

License: (c) (1) This work is licensed under a Creative Commons Attribution 4.0 International License. Read Full License 


\section{Abstract}

\section{Background}

From a series of penetrating head and neck trauma managed in a level- 1 Trauma Center, the main aim of this study was to determine predictive factors for early definitive airway management, during pre-hospital time or in the emergency room. The secondary objective was to perform a descriptive epidemiological analysis of the series.

\section{Methods}

A single-center retrospective study was conducted between January 12012 and June 30 2020. in a French Level 1 Trauma Center. The patients included were adults treated for penetrating head and neck trauma, regardless of the mechanism and the causal agent.

\section{Results}

56 patients were included. Ballistic origin, Shock Index $>0.9$ and active bleeding in the emergency room were predictive criteria for definitive airway management during pre-hospital time or in the emergency room. $78.6 \%$ of patients were male. Median age was 54 years. The trauma followed a suicide attempt in $50 \%$ of cases, an accident in $26.7 \%$ and an assault in $23.2 \%$, with use of a knife in $42.9 \%$ and firearm in $26.8 \%$. Mortality was $10.7 \% .16 .1 \%$ of patients had undergone pre-hospital intubation and $19.1 \%$ intubation in the emergency room. CT scan was performed in $87.5 \%$ of cases, surgery in $96.4 \%$ and tracheotomy in $37.5 \%$. A laryngotracheal lesion was seen in $14.2 \%$. In $50 \%$ of patients, primary admission was to intensive care.

\section{Conclusions}

Ballistic origin, Shock Index $>0.9$ and active bleeding in the emergency room were predictive criteria for early definitive airway management. This study established the profile of patients suffering from penetrating head and neck trauma managed in a Trauma Center over a period of 9 years.

\section{Background}

Penetrating head and neck trauma (PHNT) is defined as a wound crossing the cervical platysma muscle or facial superficial muscular-aponeurotic system (SMAS), whatever the mechanism or instrument. PHNT is rare in civilian contexts, but life-threatening due to the anatomic complexity and high likelihood of vascular and airway lesions[1]. The difficulty of controlling and securing the airway is a major challenge [2]. It is the second most frequent cause of avoidable death after hemorrhagic shock [3, 4].

From a series of PHNT managed in a level-1 Trauma Center over a 9-year period, the main aim of the present study was to determine predictive factors for early definitive airway management, in the pre- 
hospital phase or in the emergency room. The secondary objective was to perform a descriptive epidemiological analysis of the series.

\section{Methods}

A single-center retrospective study was conducted using the prospective database of all cases of severe trauma managed in a level-1 Trauma Center, for the period January 1st, 2012 to June 30th, 2020. According to French recommendations, all patients meeting Vittel criteria are considered as severe trauma [5]. Inclusion criteria comprised adult patient, with PHNT; exclusion criteria comprised craniocerebral wounds by temporal ballistic impact, and death during the pre-hospital phase. Analysis relied on the usual hospital database, with authorization from the CNIL data protection commission and institutional review board approval (CNIL ref.: 911461V2; IRB n: 0011873-2020-14).

Two groups were formed: PHNT requiring definitive airway management in the pre-hospital phase or emergency room (group 1), and patients with no (surveillance or surgery under local anesthesia) or elective definitive airway management (group 2). Definitive airway management is defined as the presence of a tracheal intubation with a subglottic inflated balloon connected up to the ventilation device. Airway management data comprised method (orotracheal intubation or alternatives), ease of implementation (subjective operator appreciation), efficiency and indication among uncontrolled bleeding, consciousness disorder or agitation and dyspnea. In case of orotracheal intubation failure, the alternative techniques (cricothyroidotomy, intubation via the cervical wound) were recorded.

Epidemiological data comprised age, gender, trauma mechanism, place of trauma, causal agent, mortality. Injury Severity Score (ISS) was calculated [6]. Pre-hospital transport data comprised type of transfer, type and duration of transport.

Pre-hospital data comprised vital signs, oxygen saturation $\left(\mathrm{SpO}^{2}\right)$, Shock Index (SI: : heart rate/ systolic blood pressure ; predictive of severity, with elevated mortality in case of hemodynamic instability with SI $>0.9$ ) [7], cardiorespiratory arrest, hemostasis technique, HemoCue test, and prescription of vasopressors, tranexamic acid, blood transfusion and prophylactic antibiotics.

In the emergency room, the previous data were reassessed. Any changes in hemostasis were recorded. Functional and clinical signs were assessed. PHNT was standardly described as: cervical zone I (clavicle to cricoid cartilage), II (cricoid cartilage to mandibular angle) or III (mandibular angle to skull base) according to the classical 1969 Monson classification [8]; medial or lateral with respect to the anterior edge of the sternocleidomastoid muscle; superior, middle or inferior facial zone; and right or left side. Biological data comprised: HemoCue, hemoglobinemia, blood alcohol, and arterial blood gas. Posttraumatic coagulation disorder was defined by at least one of the following: prothrombin time $<70 \%$, platelets $<150,000 / \mathrm{mm}^{3}$, or fibrinogen $<1.5 \mathrm{~g} / \mathrm{L}$. Other data comprised: imaging, endoscopy, surgery, hospital stay and department. Surgical data comprised: observed lesions and secondary tracheotomy with time to decannulation. 
Data were reported as median, range and interquartile range for quantitative data, and as percentage for qualitative data. Mann-Whitney $\mathrm{U}$ test for independent samples was used, with the significance threshold set at $p<0.05$. Quantitative data were compared between groups. Qualitative data were compared between groups on $\mathrm{chi}^{2}$ test. Data identified on univariate analysis or otherwise considered clinically relevant were selected for multivariate analysis and stepwise descending logistic regression. Analyses used IBM ${ }^{\circledR}$ SPSS ${ }^{\circledR}$ Statistics 25.0 software.

\section{Results}

Fifty-six of the 2,760 severe trauma patients admitted to the emergency department were included (flowchart: Fig. 1). PHNT accounted for an annual median $2 \%$ (range, 1.27-3.33\%) of this population.

Table 1 shows airway management data. 
Table 1

Airway management data

\begin{tabular}{|c|c|c|c|c|}
\hline & $\begin{array}{l}\text { GROUP } 1 \\
\text { pre-hospital } \\
(\mathrm{N}=9)\end{array}$ & $\begin{array}{l}\text { GROUP } 1 \\
\text { in- } \\
\text { hospital } \\
(\mathrm{N}=11)\end{array}$ & $\begin{array}{l}\text { GROUP } \\
1 \text { total } \\
(\mathrm{N}= \\
20)\end{array}$ & GROUP $2(N=36)$ \\
\hline \multirow{2}{*}{$\begin{array}{l}\text { Definitive airway } \\
\text { management } \\
\text { (DAM) }\end{array}$} & \multirow{2}{*}{$\begin{array}{l}16.1 \% \\
(9 / 56))\end{array}$} & \multirow{2}{*}{$\begin{array}{l}19.6 \% \\
(11 / 56)\end{array}$} & \multirow{2}{*}{$\begin{array}{l}35,7 \% \\
(20 / 56)\end{array}$} & - No DAM: 7,1\% (4/56) \\
\hline & & & & - Elective DAM: $57.1 \%(32 / 56)$ \\
\hline \multicolumn{5}{|l|}{ DAM: type } \\
\hline \multirow{5}{*}{$\begin{array}{l}\text { - Orotracheal } \\
\text { intubation (OTI) } \\
\text { - Cricothyroidotomy } \\
\text { - Intubation via } \\
\text { cervical wound }\end{array}$} & \multirow{2}{*}{$\begin{array}{l}-100 \% \\
(9 / 9)\end{array}$} & \multirow{2}{*}{$\begin{array}{l}-81.8 \% \\
(9 / 11)\end{array}$} & \multirow{2}{*}{$\begin{array}{l}-90 \% \\
(18 / 20)\end{array}$} & \multirow{5}{*}{$\begin{array}{l}-100 \%(32 / 32) \\
-0 \%(0 / 32) \\
-0 \%(0 / 32)\end{array}$} \\
\hline & & & & \\
\hline & $-0 \%(0 / 9)$ & $\begin{array}{l}-1.8 \% \\
(1 / 9)\end{array}$ & $\begin{array}{l}-5,6 \% \\
(1 / 18)\end{array}$ & \\
\hline & \multirow{2}{*}{$-0 \%(0 / 9)$} & $-18 \%$ & $-56 \%$ & \\
\hline & & $(1 / 9)$ & $(1 / 18)$ & \\
\hline \multicolumn{5}{|l|}{ DAM: indication } \\
\hline $\begin{array}{l}\text { - Uncontrolled } \\
\text { bleeding }\end{array}$ & $\begin{array}{l}-66.7 \% \\
(6 / 9)\end{array}$ & $\begin{array}{l}-63.6 \% \\
(7 / 11)\end{array}$ & $\begin{array}{l}-65 \% \\
(13 / 20)\end{array}$ & \multirow[t]{3}{*}{$\begin{array}{l}\text { Elective indication for surgery under } \\
\text { general anesthesia: } 100 \%(32 / 32)\end{array}$} \\
\hline $\begin{array}{l}\text { - Consciousness } \\
\text { disorder/agitation }\end{array}$ & $\begin{array}{l}-77.8 \% \\
(7 / 9)\end{array}$ & $\begin{array}{l}-45.4 \% \\
(5 / 11)\end{array}$ & $\begin{array}{l}-60 \% \\
(12 / 20)\end{array}$ & \\
\hline - Dyspnea & $-0 \%(0 / 9)$ & $\begin{array}{l}-45.4 \% \\
(5 / 11)\end{array}$ & $\begin{array}{l}-25 \% \\
(5 / 20)\end{array}$ & \\
\hline OTI: efficiency & $100 \%(9 / 9)$ & $\begin{array}{l}81.8 \% \\
(9 / 11)\end{array}$ & $\begin{array}{l}90 \% \\
(18 / 20)\end{array}$ & $100 \%(32 / 32)$ \\
\hline \multicolumn{5}{|l|}{$\begin{array}{l}\text { OTI: ease of } \\
\text { performance }\end{array}$} \\
\hline \multirow{4}{*}{$\begin{array}{l}\text { - Easy } \\
\text { - Difficult } \\
\text { - No data }\end{array}$} & \multirow{2}{*}{$\begin{array}{l}-44.4 \% \\
(4 / 9)\end{array}$} & \multirow{2}{*}{$\begin{array}{l}-55.6 \% \\
(5 / 9)\end{array}$} & \multirow{2}{*}{$\begin{array}{l}-50 \% \\
(9 / 18)\end{array}$} & $-81.2 \%(26 / 32)$ \\
\hline & & & & $-5.6 \%(2 / 32)$ \\
\hline & $11.1 \%(1 / 9)$ & $(2 / 9)$ & $\begin{array}{l}-10,18 \\
3 / 18)\end{array}$ & $-12.5 \%(4 / 32)$ \\
\hline & $\begin{array}{l}-33.3 \% \\
(3 / 9)\end{array}$ & $\begin{array}{l}-22.2 \% \\
(2 / 9)\end{array}$ & $\begin{array}{l}-27,8 \% \\
(5 / 18)\end{array}$ & \\
\hline
\end{tabular}

Univariate analysis identified in the group 1 significant differences in rates of ballistic trauma $(p=0.001)$, cervical zone III and lower face involvement $(p=0.033)$, active bleeding $(p=0.004)$, Shock Index $>0.9(p=$ $0.033)$, Glasgow score $<7(p<0.001)$, and hemoglobinemia $<10 \mathrm{~g} / \mathrm{dL}(p<0.001)$. Multivariate analysis identified a significant association between ballistic trauma, Shock Index $>0.9$ and active bleeding in emergency room and the need for early definitive airway management. 
Mortality in the overall population of severe or penetrating trauma patients was $3.6 \%(n=98)$, and $10.7 \%$ $(n=6)$ in PHNT, ranging from $33 \%(n=5)$ associated with firearms to $2.4 \%(n=1)$ for all other instruments. Causes included: multi-organ failure $(n=2)$, acute respiratory distress syndrome following a pneumonia $(n=1)$, cardiogenic shock $(n=1)$, and interruption of ongoing palliative oncologic treatment $(n=2)$. Two patients died within 24 hours, 3 on day 4 (including the 2 with treatment interruption), and 1 on day 31.

Table 2 shows epidemiological and pre-hospital transport data.

Table 2

Epidemiological and pre-hospital transport data

\begin{tabular}{|c|c|}
\hline & EPIDEMIOLOGICAL DATA \\
\hline Age & Median age, 54 years (range, $18-89$ years). \\
\hline Gender & $78.6 \%$ male $(n=44), 21.4 \%$ female $(n=12), M / F$ sex ratio of 3.67 \\
\hline $\begin{array}{l}\text { Trauma } \\
\text { mechanism }\end{array}$ & $\begin{array}{l}\text { Attempted suicide }(50 \%, n=28) \text {, fight }(23.2 \%, n=13) \text {, accident with work tool }(12.5 \%, n \\
=7) \text {, fall against blunt object }(7.1 \%, n=4) \text {, road accident }(7.1 \%, n=4)\end{array}$ \\
\hline $\begin{array}{l}\text { Location of } \\
\text { trauma }\end{array}$ & $\begin{array}{l}\text { Home }(58.9 \%, n=33) \text {, public space }(21.4 \%, n=12) \text {, workplace }(14.3 \%, n=8) \text {, vehicle } \\
(3.6 \%, n=2) \text {, prison }(1.8 \%, n=1) \text {. }\end{array}$ \\
\hline $\begin{array}{l}\text { Causal } \\
\text { agents }\end{array}$ & $\begin{array}{l}\text { knife }(42.9 \%, n=24) \text {, firearm }(26.8 \%, n=15) \text {, blunt object }(19.6 \%, n=11) \text {, work tool } \\
\text { such as chainsaw or hedge-cutter }(10.7 \%, n=6)\end{array}$ \\
\hline \multirow{2}{*}{$\begin{array}{l}\text { Injury } \\
\text { Severity } \\
\text { Score (ISS) }\end{array}$} & For $\mathrm{N}=56:$ ISS median $=13.5(2-34)$ \\
\hline & PRE-HOSPITAL TRANSPORT DATA \\
\hline $\begin{array}{l}\text { Type of } \\
\text { transfer }\end{array}$ & Primary: $87.5 \%(N=49)$, secondary: $8.9 \%(N=5)$, own means: $3.6 \%(N=2)$ \\
\hline \multirow[t]{2}{*}{$\begin{array}{l}\text { Means of } \\
\text { transport }\end{array}$} & $\begin{array}{l}\text { Emergency service: } 8.9 \%(N=5) \text {, private ambulance: } 1.8 \%(N=1) \text {, emergency medical } \\
\text { ambulance: } 60.7 \%(N=34) \text {, helicopter: } 21.4 \%(N=12) \text {, own means: } 3.6 \%(N=2) \text {, no } \\
\text { data: } 3.6 \%(N=2)\end{array}$ \\
\hline & I.e., medical transport: $83.9 \%(\mathrm{~N}=47)$ \\
\hline $\begin{array}{l}\text { Transport } \\
\text { time }\end{array}$ & $\begin{array}{l}\text { For } N=29 \text {. Time on site: } 26(10-45) \text {, mean transport time: } 20(6-50,) \text { mean total time: } \\
46(30-70)\end{array}$ \\
\hline (minutes) & Time< 1h: $72.4 \%(\mathrm{~N}=21) ;>1 \mathrm{~h}: 27.6 \%(\mathrm{~N}=8)$ \\
\hline
\end{tabular}

Table 3 shows pre-hospital and in-hospital data. 
Table 3

Pre- and in-hospital clinical data

\section{PRE-HOSPITAL DATA}

Score $\leq 8: 10.7 \%(N=6) ; 9 \leq$ Score $\leq 12: 3.6 \%$ $(\mathrm{N}=2)$; Score $>12: 85.7 \%(\mathrm{~N}=48)$; Score $=15$ : $82.1 \%(\mathrm{~N}=42)$

Glasgow score

Respiratory rate

Oxygen

saturation

$\left(\mathrm{SpO}^{2}\right)$

Shock Index (=

heart rate/

systolic blood

pressure)

Cardiorespiratory $\quad 0 \%(\mathrm{~N}=0)$

arrest

Hemostasis

None: $1.8 \%(\mathrm{~N}=1)$; simple dressing: $23.2 \%(\mathrm{~N}$ = 13); compressive dressing: $58.9 \%(\mathrm{~N}=33)$; manual compression: $7.1 \%(\mathrm{~N}=3)$; suture: $1.8 \%(\mathrm{~N}=1)$; no data: $8.9 \%(\mathrm{~N}=5)$; hemostatic agent: $5.3 \%(\mathrm{~N}=3)$

For $\mathrm{N}=42: \mathrm{SI}$ median $=0.74: \mathrm{SI}<0.9: 69.1 \%$

$(\mathrm{N}=29): \mathrm{SI}>0.9: 30.9 \%(\mathrm{~N}=13)$

For $\mathrm{N}=50: \leq 95 \%: 18 \%(\mathrm{~N}=9):>95 \%: 82 \%(\mathrm{~N}$ $=41$ )

IN-HOSPITAL DATA

Score unchanged: $87.5 \%(\mathrm{~N}=$ 49); deteriorated: $8.9 \%(\mathrm{~N}=5)$; improved: $3.6 \%(\mathrm{~N}=2$ : initial voice loss after attempted suicide)

For $\mathrm{N}=32$ : mean: $18 / \mathrm{min}(12-$ 39)

For $\mathrm{N}=49: \leq 95 \%: 16.3 \%(\mathrm{~N}=$ 8); > 95\%: 83.7\% ( $\mathrm{N}=41)$

For $\mathrm{N}=49$ : $\mathrm{SI}$ median $=0.7 . \mathrm{SI}$ < 0.9: $77.6(\mathrm{~N}=38): ; \mathrm{SI}>0.9$ : $22.4 \%(\mathrm{~N}=11)$

$5.4 \%(\mathrm{~N}=3)$

Hemostatic action: $33.9 \%(\mathrm{~N}=$ $19)$; no change: $66.1 \%(\mathrm{~N}=37)$

Compressive dressing: $84.2 \%$ (16/19); oral and/or nasal packing: $21.1 \%(4 / 19)$; suture: $15.8 \%(3 / 19)$; hemostatic agent: $26.3 \%(N=5 / 19)$

HemoCue For $\mathrm{N}=34$ : mean HemoCue $=12.8 \mathrm{~g} / \mathrm{dL}(4-$ 18)

Hemoglobinemia /

Blood gas

/

/

Traumatic coagulopathy

Positive blood / alcohol

$(>0.1 \mathrm{~g} / \mathrm{L})$

Vasopressors $\quad$ For $\mathrm{N}=47: 8.5 \%(\mathrm{~N}=4)$

Transfusion (red For $\mathrm{N}=47: 8.5 \%(\mathrm{~N}=4)$ blood packs)
$17.9 \%(\mathrm{~N}=10)$

For $\mathrm{N}=40$ : mean HemoCue $=$ $11.7 \mathrm{~g} / \mathrm{dL}(5.4-15.6)$

Mean $=12.6 \mathrm{~g} / \mathrm{dL}(7.8-16)$

pH median: 7.36 (6.75-7.54): lactatemia median: 2.1 $\mathrm{mmol} / \mathrm{L}(0.8-23)$

$8.9 \%(N=5)$

Yes: $12.5 \%(\mathrm{~N}=7)$; no: $60.7 \%$ $(\mathrm{N}=34)$; no data: $28.6 \%(\mathrm{~N}=$ 16)

$9.8 \%(\mathrm{~N}=5)$ 


\begin{tabular}{|c|c|c|}
\hline & PRE-HOSPITAL DATA & IN-HOSPITAL DATA \\
\hline Tranexamic acid & $\begin{array}{l}\text { For } N=47: \text { yes: } 44.7 \%(N=21) \text { no: } 38.3 \%(N= \\
\text { 18); no data: } 17 \%(N=8)\end{array}$ & $\begin{array}{l}\text { Yes: } 19.6 \%(\mathrm{~N}=11) \text {; no: } \\
76.8 \%(\mathrm{~N}=43) \text {; no data: } 3.6 \% \\
(\mathrm{~N}=2)\end{array}$ \\
\hline $\begin{array}{l}\text { Antibiotic } \\
\text { prophylaxis }\end{array}$ & $\begin{array}{l}\text { For } N=47 \text { : yes: } 29.8 \%(N=14) ; \text { no: } 53.2 \%(N= \\
25) ; \text { no data: } 17 \%(N=8)\end{array}$ & $\begin{array}{l}\text { Yes: } 26.8 \%(N=15) ; \text { no: } \\
67.8 \%(N=38) ; \text { no data: } 5.4 \% \\
(N=3)\end{array}$ \\
\hline
\end{tabular}

Table 4 and Fig. 2 show functional and clinical signs and affected structures. 
Table 4

Functional and clinical signs and affected structures.

\begin{tabular}{|c|c|}
\hline \multirow{3}{*}{$\begin{array}{l}\text { Functional } \\
\text { signs }\end{array}$} & - Dysphonia (8.9\%. $N=5)$; upper dyspnea $(10.7 \% . N=6)$ \\
\hline & - Hemoptysis (23.2\%. $\mathrm{N}=12)$; hematemesis (3.6\%. $\mathrm{N}=2$ ) \\
\hline & $\begin{array}{l}\text { - Uncontrolled active bleeding }(28.6 \% . N=16) \text {, compressed }(19.6 \% . N=11 \text { or } \\
\text { checked }(51.8 \% . N=21)\end{array}$ \\
\hline \multirow[t]{11}{*}{ Clinical signs } & - Sucking cervical wound $(7.1 \% . \mathrm{N}=4)$ \\
\hline & - Subcutaneous emphysema $(14.3 \% . \mathrm{N}=8)$ \\
\hline & - Cervical hematoma $(44.6 \% . \mathrm{N}=25)$ \\
\hline & - Neurologic deficit \\
\hline & o facial nerve $(12.5 \% . \mathrm{N}=7)$ \\
\hline & o vagus nerve $(5.4 \% . \mathrm{N}=3)$ \\
\hline & o accessory nerve $(3.6 \% . \mathrm{N}=2)$ \\
\hline & o hypoglossal nerve $(1.8 \% . \mathrm{N}=1)$ \\
\hline & o brachial plexus $(3.6 \% . \mathrm{N}=2)$ \\
\hline & o Claude-Bernard Horner syndrome $(5.4 \% . \mathrm{N}=3)$ \\
\hline & o medullary deficit $(0 \% . \mathrm{N}=0)$ \\
\hline \multirow{5}{*}{$\begin{array}{l}\text { Affected head } \\
\text { and neck } \\
\text { structures }\end{array}$} & - Principal salivary glands $(17.9 \% . N=10)$; thyroid gland $(8.9 \% . N=5)$ \\
\hline & - Trachea $(7.1 \% . \mathrm{N}=4)$; larynx $(7.1 \% . \mathrm{N}=4)$ \\
\hline & - Pharynx $(7.1 \% . N=4)$; cervical esophagus $(0 \% . N=0)$ \\
\hline & - External ear $(3.6 \% . \mathrm{N}=2)$ : nasal pyramid $(12.5 \% . \mathrm{N}=7)$. \\
\hline & $\begin{array}{l}\text { - Vascular: internal jugular vein }(10.7 \% . \mathrm{N}=6) \text {; external carotid artery or branch } \\
(16.1 \% . \mathrm{N}=9) ; \text { common or internal carotid artery }(7.1 \% . \mathrm{N}=4) \text {; carotid sheath } \\
\text { contusion }(3.6 \% . \mathrm{N}=2)\end{array}$ \\
\hline \multirow{2}{*}{$\begin{array}{l}\text { Affected non- } \\
\text { H\&N } \\
\text { structures }\end{array}$} & - Multiple $(53.6 \% . N=30)$ \\
\hline & $\begin{array}{l}\text { - Ophthalmic }(14.3 \% . N=8) \text { - neurosurgical }(19.6 \% . N=11)-\text { orthopedic }(23.2 \% . N \\
=13) \text { - thoracic }(12.5 \% . N=7) \text { - digestive }(10.7 \% . N=6)-\text { peripheral vascular }(3.6 \% \text {. } \\
N=2)\end{array}$ \\
\hline
\end{tabular}

Complementary examinations comprised contrast-enhanced CT in $87.5 \%$ of cases $(n=49)$, flexible endoscopy in $14.3 \%(n=8)$, esophagogastroduodenal endoscopy in $5.4 \%(n=3)$, tracheobronchial endoscopy in 3.6\% $(n=2)$ and FAST (Focused Assessment with Sonography in Trauma) ultrasound in $46.4 \%(n=26) .96 .4 \%$ of patients ( $n=54)$ underwent surgery under local (in $3.7 \%$ of cases, $n=2$ ) or general anesthesia (in $96.3 \%, n=52$ ). One patient was admitted for surveillance, and another was not operated on as treatment limitation. $50 \%$ of patients $(n=28)$ were admitted for a mean 2 days (range, $0-$ 
18 days) to intensive or continuous care before transfer to conventional surgery for a mean total stay of 11 days (range, $1-94$ days).

There was 1 external and 2 internal carotid ligations, and 1 end-to-end internal carotid anastomosis. Interventional radiology was required in 1 case (1.8\%). Two patients required ocular enucleation. Two patients underwent neurosurgery: 1 for craniocerebral wound care, and 1 for decompressive craniotomy. One patient showed cervical spine trauma: C5-C6-C7-T1 transverse apophyses with vertebral artery dissection. $28.6 \%$ of patients $(n=16)$ underwent non-head-and-neck surgery: limb fractures $(5.4 \%, n=3)$, pneumothorax $(8.9 \%, n=5)$, and wounds to the lung $(3.6 \%, n=2)$, heart $(5.4 \%, n=3)$, liver $(3.6 \%, n=2)$, stomach $(3.6 \%, n=2)$, colon $(3.6 \%, n=2)$, diaphragm $(3.6 \%, n=2)$, hand $(8.9 \%, n=5)$, or soft tissue $(14.3 \%, n=8)$. No tracheotomy was performed as an alternative technique in case of failure after attempted orotracheal intubation. Only during surgery, secondary tracheotomy was performed in $37.5 \%$ of cases $(n=21)$. Tracheotomies were performed to free up space in operative field, to relay a cricothyroidotomy or to shorten the post-traumatic oedema. All patients were decannulated, at a median 15 days (range, 2-120 days).

\section{Discussion}

The present study has the particular interest of being the first descriptive report of a series of PHNT in civilian practice in a French Trauma Center, over a long 9-year period at the level of a whole administrative area (Département). The single-center design ensured homogeneity of practices and thus of data. Although conducted retrospectively, the study was based on prospectively collected data from a database allowing epidemiological comparison between PHNT and the severe trauma population as a whole. It also provided precise analysis of the issue of airway management in PHNT, which has been rarely addressed specifically in the literature. Predictive factors for early definitive airway management were identified.

\section{Airway Management}

Acute respiratory failure is seen in $10-50 \%$ of cases, by direct obstruction, extrinsic compression, partial or total airway sectioning, or of neurologic origin. It is consensual that airway control, despite the difficulty of the approach, should be anticipated due to the risk of rapid respiratory distress [9]. In the present series, orotracheal intubation was difficult in $12.5 \%$ of cases, and in $25 \%$ when performed in emergency in group 1 , versus $5.6 \%$ in group 2 . In case of dyspnea in the emergency room $(n=6)$, intubation failed in $33.4 \%$ of cases, and in $100 \%$ in case of associated cervical emphysema or sucking wound. In combat, upper airway obstruction is the second cause of preventable death, after hemorrhage and ahead of compressive pneumothorax [2-4]. According to Demetriades [10] about $16 \%$ of firearm injuries and $14 \%$ of knife wounds are associated with pneumothorax; the rate was $8.9 \%$ in the present series. Cases where both chest X-ray and FAST proved negative involved anteroinferior pneumothorax following sub-xyphoid knife wound. This association is more frequent in zone I trauma $(80 \%$ in the present series). 
When release maneuvers and mask oxygen therapy fail, definitive airway treatment is required, with tracheal intubation with a subglottic inflated balloon connected up to the ventilation device. Even with a cricothyroidotomy kit, a balloon should be used. The present series confirmed frequent radiological signs of pulmonary inhalation. Once the airway is secured, oronasal packing is possible and effective. Prehospital and in-hospital algorithms determine the roles of 3 types of definitive airway: orotracheal, nasotracheal, and cervical intubation (cricothyroidotomy, tracheotomy, intubation via sucking cervical wound). Urgency and circumstances determine the method to be used. Laryngoscopic orotracheal intubation is the method of choice, with gum elastic bougie in case of difficulty. In case of failure, supraglottic airway and videolaryngoscopy can be attempted by experienced operator [11], but are likely to fail due to anatomical distorsion and/or soiling of the airway by blood. Prompt escalation to a surgical airway must be quickly considered. Cricothyroidotomy is the technique of choice. Tracheotomy is an option, but is a surgical procedure, difficult to implement in emergency [12], with dissection liable to incur blood loss for several minutes, thus not an adapted salvage procedure. It is, however, indicated secondarily to orotracheal intubation to free the operative field, improving patient comfort with earlier awakening, despite the post-traumatic pharyngolaryngeal edema. Tracheotomy is performed within hours of cricothyroidotomy, to avoid secondary laryngeal stenosis. Thus, in the present series, secondary tracheotomy was performed in $37.5 \%$ of cases. All were subsequently decannulated. In rare cases of laryngeal or tracheal sectioning with complete airway obstruction, direct insertion of the intubation probe or tracheotomy cannula through the lesion is the optimal means of airway control. We recommend systematically having Laborde forceps in the pre-hospital kits and emergency trolleys.

Optimal airway control makes orotracheal intubation difficult or even risky when performed at the accident site: risk of inhalation on a full stomach, risk of spinal instability, presence of a cervical collar, altered anatomic relations, mechanical limitation of oral opening, and blood loss into the oropharynx [13]. Nevertheless, orotracheal intubation remains mandatory in case of respiratory distress or severe cyanosis. In contrast, indications are trickier in apparently stable patients. But the literature reports no significant predictive criteria for early definitive airway management. Despite its limitations, the present study identified three: ballistic cause of trauma, hemodynamic impact with Shock Index $>0.9$, and active bleeding in the emergency room. It also identified trends for certain criteria: submental impact with involvement of cervical zone III and the lower face, neurologic impact with Glasgow score $<7$, and hemoglobinemia $<10 \mathrm{~g} / \mathrm{dL}$. Irretrievable loss of substance leads to difficulties hemostasis with blood loss and difficulties temporary airway control maneuvers. Prolonged transfer to hospital is a classical factor in favor of early preventive airway salvage, perhaps in conditions such as helicopter transport in which intubation is difficult. In the present series, only one cricothyroidotomy was performed in the emergency room, in a patient with dyspnea and progressive cervical hematoma following a submental ballistic suicide attempt, who had not been intubated ahead of helicopter transport that took more than an hour (Fig. 4).

Even so, the decision to intubate is always very difficult; if considered, it should be performed as quickly as possible while conditions are still favorable. A further multicenter study based on a national registry 
could increase statistical power and help determine optimal definitive airway management timing, notably according to transport time.

\section{Descriptive epidemiological analysis of the series}

PHNT is rare, at $5-10 \%$ of traumas treated in emergency [14], and $2 \%$ in the present series. Incidence varies geographically, and is higher in American and South African series [10, 13, 15]. In Europe, incidence is lower: 4.3/100,000 per year in London, UK [16]], and 1.3/100,000 per year in Finland [17]. Over the present study period, the median annual emergency department turnover was 34,600 patients, with 310 cases of severe trauma and 1 of PHNT every 2 months. Management is familiar in military contexts: warscene incidence is 5-10\% [18]; poor head and neck ballistic protection and asymmetric conflicts featuring improvised explosive devices (IEDs) led to increased incidence, reaching 36-55\%, in French troops in Afghanistan $[19,20]$. In line with the literature [16], we found male predominance and a median age around 50 years.

Frequency also varies according to circumstances and instrument. In Los Angeles [10] PHNT is caused by aggression or attempted suicide by firearms in $48 \%$ of cases, by knife wounds in $40 \%$ and blunt objects (road accidents or falls) in $10 \%$. In the present series, $50 \%$ of cases also concerned attempted suicide, by violent means inasmuch as $86.7 \%$ of ballistic PHNTs were suicide attempts. PHNT accounts for $1.6-3 \%$ of suicide attempts as a whole [21], but is one of the most lethal means [22]. The instrument was more often a knife (42.9\%) than a firearm (26.8\%), probably because the latter are less readily available in France than in the USA. In wartime, the distribution is different, with $62-98 \%$ of cases involving highvelocity weapons $[19,23]$.

Mortality is between $3 \%$ and $6 \%$, mainly due to massive blood loss from large vessels [1]; it is generally underestimated, as most studies exclude pre-hospital mortality, for lack of data; if this is included, mortality can be as high as $11 \%$ [19]. Nevertheless, in our series, no deaths by exsanguination were found. These patients at high risk of rapid hemodynamic and respiratory decompensation need urgent medical transport to the nearest Trauma Center [24]. In the present series, despite a mean transport time of 46 minutes (72.4\% with respect to the "Golden Hour" [25]) and pre-hospital medical care in $82.1 \%$ of cases, mortality was $10.7 \%$ (not including pre-hospital deaths). In severe trauma as a whole, mortality is higher than specifically in PHNT. The present high mortality may be due to the small sample and to a recruitment bias with two treatment interruptions prescribed due to the severity of neurologic lesions in a context of advanced cancer. In $83.3 \%$ of cases, death was due to ballistic trauma in attempted suicide, impacting the submental central compartment in zone III. The only patient who died after isolated cervical trauma (zone II) showed total sectioning of the internal carotid artery and pharynx, after falling onto a metal picket (Fig. 3).

As in the literature [10], zone II predominated in purely cervical trauma, at 56.2\%. The "central/lateral" classification separates the vascular axis and aerodigestive tract [19]. In the present series, the lateral compartment was the most involved (66.1\%). $74 \%$ of cervical lesions ( $42.9 \%$ in the present series) are on the left side [26], aggressors tending to be right-handed. 
Treatment in PHNT used to involve systematic surgical exploration of any wound crossing the platysma, but surgery has now become more selective [27]. Several prospective series supported selective surgery, and described algorithms $[1,15,28]$. In the present series, $87.5 \%$ of patients underwent contrast-enhanced CT, and $96.4 \%$ underwent surgery. Only 1 patient was treated non-operatively, by in-hospital surveillance. In some patients, surgical exploration confirmed the absence of life-threatening lesions, and CT findings were never falsified. Even so, simple surgical damage control with exploration to check hemostasis (especially in dry venous wounds following knife attacks), prevention of superinfection by lavage, wound care and debridement, extraction of any foreign bodies, possibly with drainage, and suturing in 2 planes was always essential. The sole indication for interventional neuroradiology was for a lateral zone III knife wound with internal carotid thrombosis. According to some authors [29-31], algorithms based on entry point are too rigid, leading to unproductive surgery, overlooked lesions with poor correlation between the location of the external wound and the internal lesions, increased hospital stay, and higher rates of complications. In 2018, Nowicki [24] described a selective attitude, independent of cervical zone, taking the whole neck as a single entity. Even so, we consider these classifications useful, especially when there is an influx of injured patients and imaging is not available, as often happens in military surgery overseas, where the surgeon is seldom specialized in head and neck. The classifications help mentalize the lesion trajectory, disclosing vascular involvement in lateral lesions or respiratory involvement in central lesions, and determining optimal strategy in borderline zones I and III.

\section{Conclusion}

The present study, conducted at the level of a French regional Trauma Center, confirmed that penetrating head and neck trauma is rare, but with a high morbi-mortality, especially in case of firearm trauma.

Securing the airway is a major challenge, especially before a prolonged transport. Ballistic origin, Shock Index $>0.9$ and active bleeding in the emergency room were predictive criteria for early definitive airway management. Prompt intubation should be considered.

\section{Declarations}

\section{Ethics approval and consent to participate}

Analysis relied on the usual hospital database, with authorization from the CNIL data protection commission and institutional review board approval (CNIL ref.: 911461V2; IRB n: 0011873-2020-14).

\section{Consent for publication}

Consent for publication was obtained for individual person's data in figures.

\section{Availability of data and materials}


The dataset supporting the conclusions of this article is included within the article and its additional file.

\section{Competing interests}

The authors declare that they have no competing interests.

\section{Funding}

Not applicable.

\section{Authors' contributions}

JC, AR, VM, DP, NB, LV, DR, CJ have contributed to the conception of the work.

PJC, JC, CMB, OC, JB have contributed to the design of the work.

$\mathrm{CMB}, \mathrm{DM}, \mathrm{VM}$ have contributed to the acquisition of data.

PJC, CMB, JB have contributed to the analysis of data.

PJC, JC, JB have contributed to the interpretation of data.

JC, AR, OC, JB have substantively revised the work.

All authors read and approved the final submitted manuscript.

\section{Acknowledgements}

The authors would like to thank all the prehospital and hospital teams for their collaboration in the care of patients.

\section{Declaration of interest}

The authors have no conflicts of interest.

\section{References}

1. Burgess CA, Dale OT, Almeyda R, Corbridge RJ. An evidence based review of the assessment and management of penetrating neck trauma. Clin Otolaryngol Off J ENT-UK Off J Neth Soc Oto-RhinoLaryngol Cervico-Facial Surg. 2012;37:44-52. 
2. Lairet JR, Bebarta VS, Burns CJ, Lairet KF, Rasmussen TE, Renz EM, et al. Prehospital interventions performed in a combat zone: a prospective multicenter study of 1,003 combat wounded. J Trauma Acute Care Surg. 2012;73:S38-42.

3. Adams BD, Cuniowski PA, Muck A, De Lorenzo RA. Registry of emergency airways arriving at combat hospitals. J Trauma. 2008;64:1548-54.

4. Eastridge BJ, Hardin M, Cantrell J, Oetjen-Gerdes L, Zubko T, Mallak C, et al. Died of wounds on the battlefield: causation and implications for improving combat casualty care. J Trauma. 2011;71:S4-8.

5. Cotte J, Courjon F, Beaume S, Prunet B, Bordes J, N'Guyen C, et al. Vittel criteria for severe trauma triage: Characteristics of over-triage. Anaesth Crit Care Pain Med. 2016;35:87-92.

6. Domingues C de A, Coimbra R, Poggetti RS, Nogueira L de S, de Sousa RMC. New Trauma and Injury Severity Score (TRISS) adjustments for survival prediction. World J Emerg Surg WJES. 2018;13:12.

7. Campos-Serra A, Montmany-Vioque S, Rebasa-Cladera P, Llaquet-Bayo H, Gràcia-Roman R, ColomGordillo A, et al. The use of the Shock Index as a predictor of active bleeding in trauma patients. Cirugia Espanola. 2018;96:494-500.

8. Monson DO, Saletta JD, Freeark RJ. Carotid vertebral trauma. J Trauma. 1969;9:987-99.

9. Combes X, Jabre P, Jbeili C, Leroux B, Bastuji-Garin S, Margenet A, et al. Prehospital standardization of medical airway management: incidence and risk factors of difficult airway. Acad Emerg Med Off $\mathrm{J}$ Soc Acad Emerg Med. 2006;13:828-34.

10. Demetriades D, Theodorou D, Cornwell E, Berne TV, Asensio J, Belzberg H, et al. Evaluation of penetrating injuries of the neck: prospective study of 223 patients. World J Surg. 1997;21:41-7; discussion 47-48.

11. Frerk C, Mitchell VS, McNarry AF, Mendonca C, Bhagrath R, Patel A, et al. Difficult Airway Society 2015 guidelines for management of unanticipated difficult intubation in adults. Br J Anaesth. 2015;115:827-48.

12. Combes X, Pean D, Lenfant F, Francon D, Marciniak B, Legras A. [Difficult airway-management devices. Establishment and maintenance: question 4. Société Française d'Anesthésie et de Réanimation]. Ann Fr Anesth Reanim. 2008;27:33-40.

13. Lefort H, Cesareo E, Domanski L, Tourtier JP, Tazarourte K. [Penetrating neck injuries: importance of one systematic clinical examination associated with a MDCT angiography]. Ann Fr Anesth Reanim. 2014;33:188-90.

14. Núñez DB, Torres-León M, Múnera F. Vascular injuries of the neck and thoracic inlet: helical CTangiographic correlation. Radiogr Rev Publ Radiol Soc N Am Inc. 2004;24:1087-98; discussion 10991100.

15. Thoma M, Navsaria PH, Edu S, Nicol AJ. Analysis of 203 patients with penetrating neck injuries. World J Surg. 2008;32:2716-23.

16. Harris R, Olding C, Lacey C, Bentley R, Schulte KM, Lewis D, et al. Changing incidence and management of penetrating neck injuries in the South East London trauma centre. Ann R Coll Surg Engl. 2012;94:240-4. 
17. Pakarinen T-K, Leppäniemi A, Sihvo E, Hiltunen K-M, Salo J. Management of cervical stab wounds in low volume trauma centres: systematic physical examination and low threshold for adjunctive studies, or surgical exploration. Injury. 2006;37:440-7.

18. Breeze J, Allanson-Bailey LS, Hunt NC, Delaney RS, Hepper AE, Clasper J. Mortality and morbidity from combat neck injury. J Trauma Acute Care Surg. 2012;72:969-74.

19. de Régloix SB, Baumont L, Daniel Y, Maurin O, Crambert A, Pons Y. Comparison of Penetrating Neck Injury Management in Combat Versus Civilian Trauma: A Review of 55 Cases. Mil Med. 2016;181:935-40.

20. Joubert C, Dulou R, Delmas JM, Desse N, Fouet M, Dagain A. Military neurosurgery in operation: experience in the French role-3 medical treatment facility of Kabul. Acta Neurochir (Wien). 2016;158:1453-63.

21. Byard RW, Klitte A, Gilbert JD, James RA. Clinicopathologic features of fatal self-inflicted incised and stab wounds: a 20-year study. Am J Forensic Med Pathol. 2002;23:15-8.

22. Sgardello SD, Christodoulou M, Abbassi Z. Anatomy of a Suicide: A Case Report. Am J Case Rep. 2019;20:1801-4.

23. Brennan J, Lopez M, Gibbons MD, Hayes D, Faulkner J, Dorlac WC, et al. Penetrating neck trauma in Operation Iraqi Freedom. Otolaryngol-Head Neck Surg Off J Am Acad Otolaryngol-Head Neck Surg. 2011;144:180-5.

24. Nowicki JL, Stew B, Ooi E. Penetrating neck injuries: a guide to evaluation and management. Ann $R$ Coll Surg Engl. 2018;100:6-11.

25. Harmsen AMK, Giannakopoulos GF, Moerbeek PR, Jansma EP, Bonjer HJ, Bloemers FW. The influence of prehospital time on trauma patients outcome: a systematic review. Injury. 2015;46:602-9.

26. Demetriades D, Charalambides D, Lakhoo M. Physical examination and selective conservative management in patients with penetrating injuries of the neck. Br J Surg. 1993;80:1534-6.

27. Wang Y, Sun Y, Zhou T, Liu G-H, Zhang X-M, Yue J-X, et al. Penetrating neck trauma caused by a rebar: A case report. Medicine (Baltimore). 2018;97:e0468.

28. Teixeira F, Menegozzo CAM, Netto SD do C, Poggeti RS, Collet E Silva F de S, Birolini D, et al. Safety in selective surgical exploration in penetrating neck trauma. World J Emerg Surg WJES. 2016;11:32.

29. Low GMI, Inaba K, Chouliaras K, Branco B, Lam L, Benjamin E, et al. The use of the anatomic "zones" of the neck in the assessment of penetrating neck injury. Am Surg. 2014;80:970-4.

30. Roepke C, Benjamin E, Jhun P, Herbert M. Penetrating Neck Injury: What's In and What's Out? Ann Emerg Med. 2016;67:578-80.

31. Shiroff AM, Gale SC, Martin ND, Marchalik D, Petrov D, Ahmed HM, et al. Penetrating neck trauma: a review of management strategies and discussion of the "No Zone" approach. Am Surg. 2013;79:239.

\section{Figures}




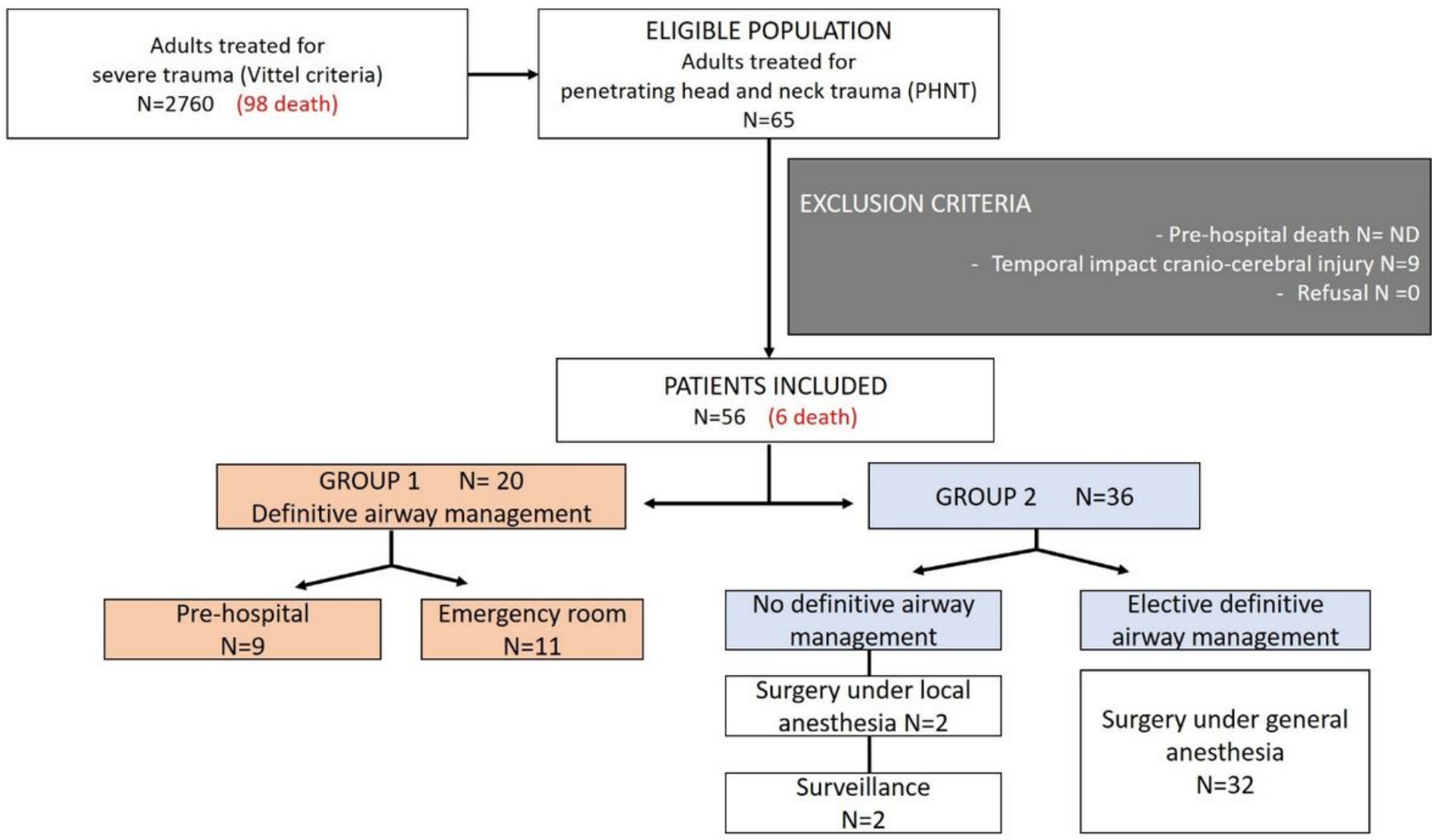

\section{Figure 1}

Population flow chart (ND: no data). 


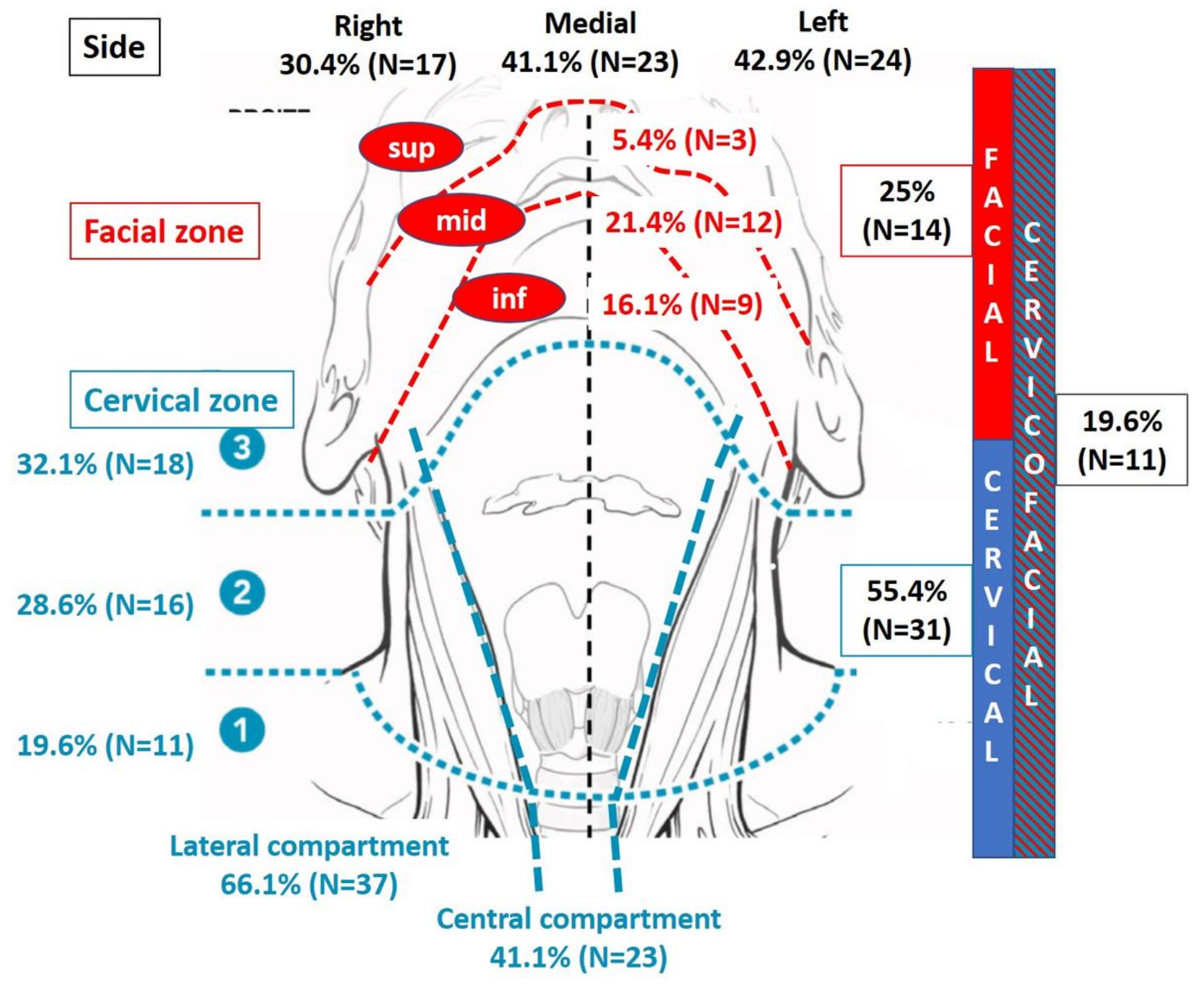

Figure 2

Distribution and laterality of injured anatomical zones (sup: superior; mid: middle; inf: inferior). 


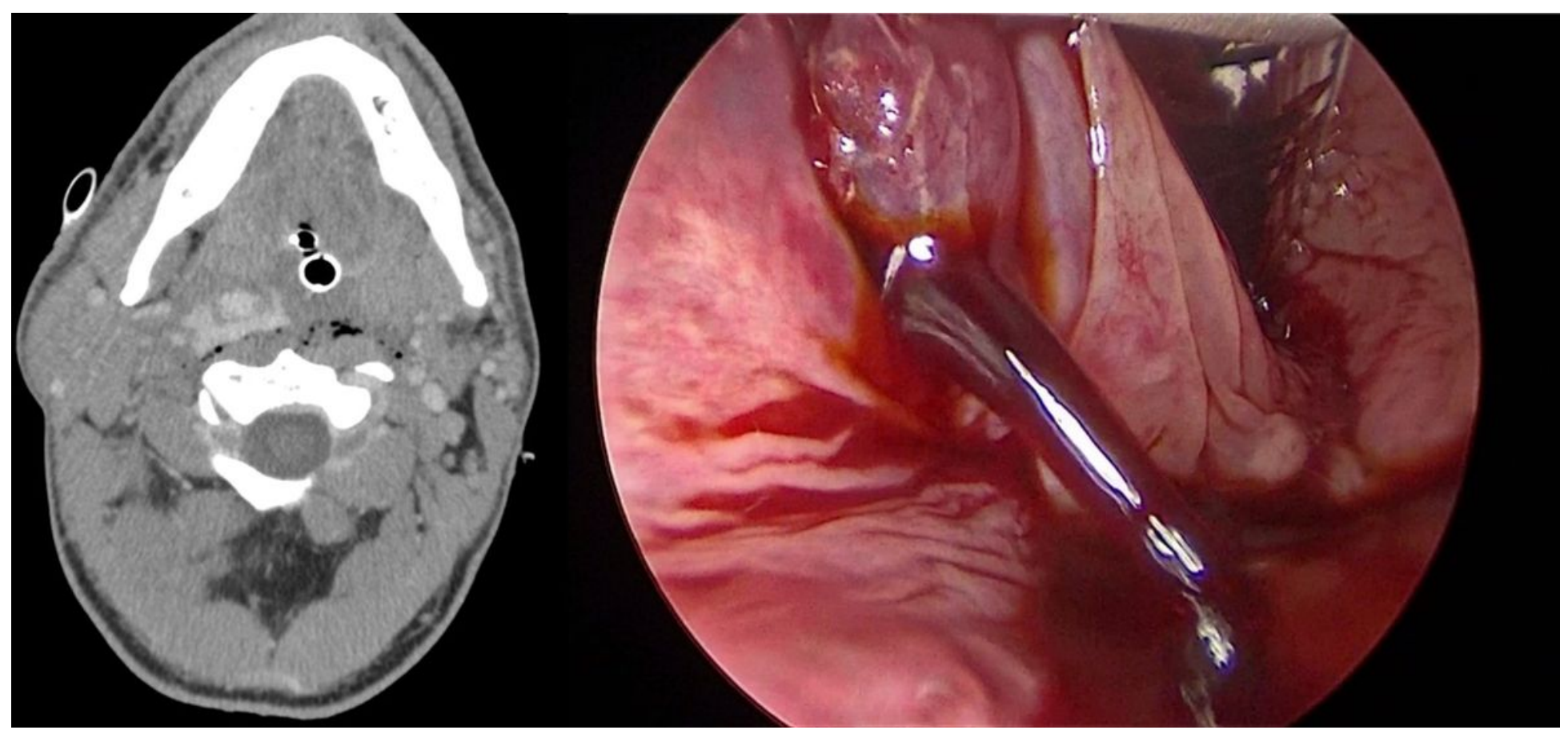

\section{Figure 3}

Cervical angio-CT-scan in axial section and intraoperative view in suspension laryngoscopy. Internal carotid artery rupture and massive hemorrhagic inhalation through a hypopharyngeal wound after fall on a metal stake with lateral zone 2 PHNT. 


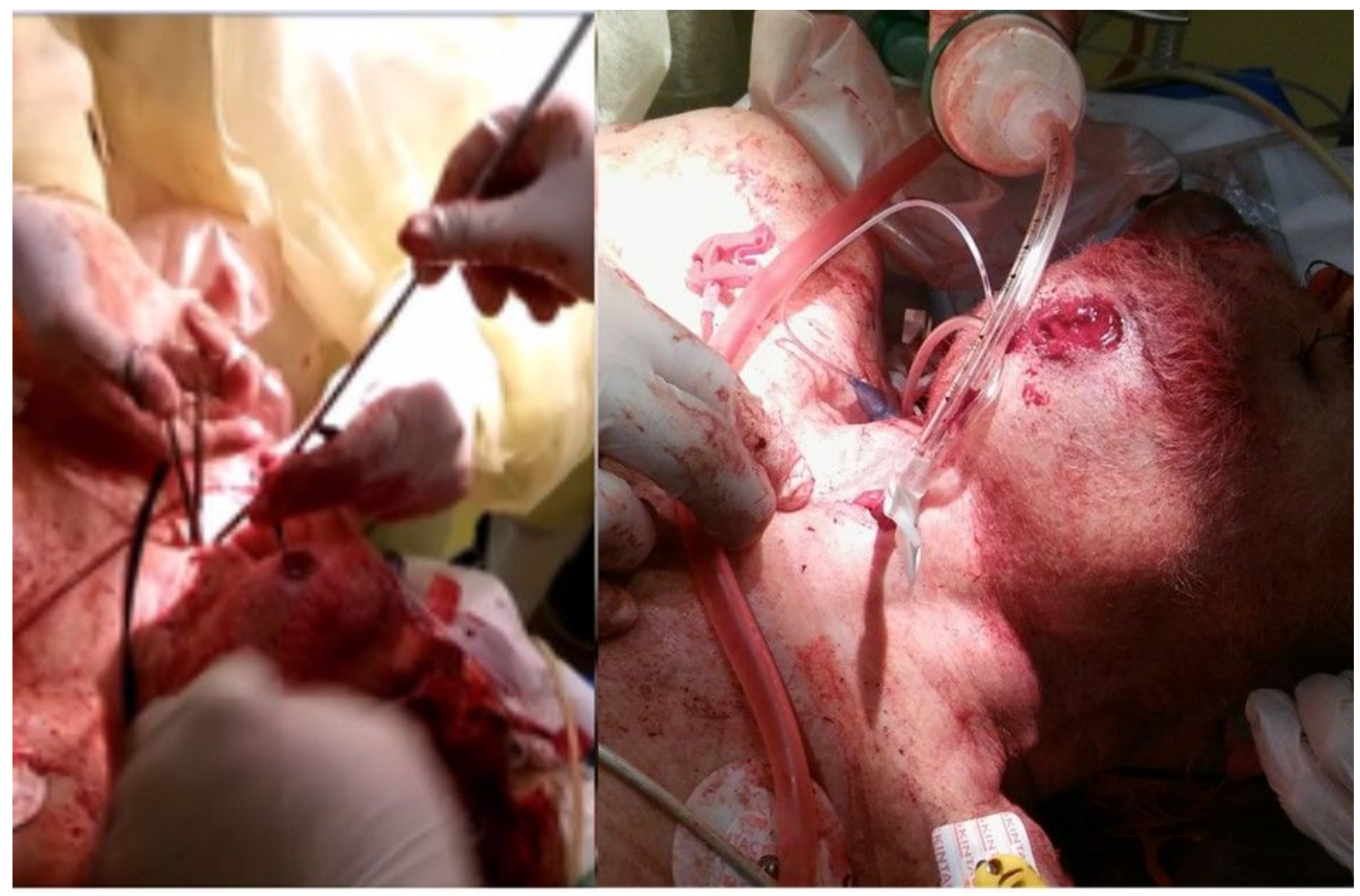

Figure 4

Rescue cricothyroidotomy in the emergency room, after failure of two orotracheal intubation attempts in a patient in hypoxic cardiorespiratory arrest, with ballistic PHNT with expansive cervical hematoma in central zone III. 